\title{
Generalized Roughness Bearing Faults Diagnosis Based on Induction Motor Stator Current
}

\author{
Ignas ANDRIJAUSKAS, Mindaugas VAITKUNAS, Rimas ADASKEVICIUS
}

Dept. of Electric Power Systems, Kaunas University of Technology, Studentu st. 48-144a, LT-51367 Kaunas, Lithuania

\{ignas.andrijauskas, mindaugas.vaitkunas, rimas.adaskevicius\}@ktu.edu

Submitted April 24, 2018 / Accepted September 4, 2018

\begin{abstract}
Despite their reliability, induction motors tend to fail. Around $41 \%$ of faults in motors are bearing related and that is the most common fault in motor field. Due to the lack of research on generalized roughness bearing fault diagnostics by use of a stator current spectrum, the presented study analyses both single-point and generalized roughness bearing faults and their classification possibilities. In this paper, a new method for generalized roughness ball bearing fault identification by use of a stator current signal analysis is presented. The algorithm relies on Discrete Wavelet Transform and Welch's spectral density analysis. The composition of both methods is used for building a feature vector for the classifier. In order to achieve classification, support vector machine classifier with linear kernel function has been applied. The validation experiment and results are presented.
\end{abstract}

\section{Keywords}

Induction motor, stator current spectrum, wavelet decomposition, Welch's spectral density, bearing fault diagnosis

\section{Introduction}

Due to their simplicity and reliability Induction Motors (IM) are the most popular in the world. They demonstrate the following features: low-cost, high-performance, easy management and resistance to harmful environments. Such electric motors consume approximately $40-50 \%$ of the electrical power produced in the world [1]. Despite the reliability of IM, like every equipment, they are tend to fail. However, the permanent monitoring system of a motor is often not used. Around $41 \%$ of all faults in motors are bearing related [2]. It is the most common fault in the IM. Costly consequences of the accident and unplanned stopping of production can be avoided by the help of early diagnosis of bearing failure.

All bearing related failures can be classified into two main groups - Single Point (SP) and Generalized Roughness (GR). This classification was introduced in [3] and became worldwide known. A Single Point type fault is defined as a single, localized defect on an otherwise relatively undamaged bearing surface. Single Point fault produces specific fault frequencies depending on which surface of the bearing occurs the fault [4]. These predictable frequency components typically appear in the machine vibration and are often reflected in the stator current. Generalized Roughness is a type of fault when the condition of a bearing surface over a large area has considerably degraded and became rough, irregular, or deformed. Generalized Roughness is a more common failure type than Single Point. Pollutant contaminated oil, shortage of oil, shaft currents and system misalignment are major causes of GR failure.

Although SP malfunctioning in ball bearings is less common, the number of methods for detecting this fault is significantly higher. This is due to the fact that the spectral components of the SP fault are clearly detected in regions calculated by well-known equations [3]. Due to the lack of research on GR diagnostics by use of a stator current spectrum, the presented work analyses both SP and GR faults and their classification possibilities. The presented method is designed for International Electrotechnical Commission (IEC) low voltage induction motors. In this context, low voltage refers to motors that operate at voltages less than $1000 \mathrm{~V}$ and produce a maximum power of $1000 \mathrm{~kW}$.

The goal of this study is to determine the ability of GR fault identification using a stator current signal, investigate whether this failure can be distinguished from the failure of the SP, and to study the relationship of the fault representing features and motor speed.

\section{Review of Methods}

One of the most popular bearing fault detection methods is the measurement of vibration. This method can be used for detection both, an SP [4] and GR failure [3]. It is important to note that the sensor must be attached to the stationary motor part [5]. Due to the popularity, there are also standards (ISO 10816) regulating motor vibration measurement. The main disadvantages of the above said method is the price of vibration sensors and the necessity to physically access the motor while measuring vibrations. In noisy environment, bearings generated low-frequency vibrations are 
overshadowed by a more strong environmental noise. In such environments the diagnosis of a motor status by vibration analysis is unreliable [6]. The emission of high-frequency stress-wave, otherwise known as acoustic emissions, can be recorded using acoustic emission sensors. Compared to conventional vibration monitoring, the acoustic emission method has got a higher signal-to-noise ratio in noisy environments. The disadvantage of this method is a high cost. Additionally, specific knowledge and experience is required for measurement of acoustic emissions. It is well known fact that faulty bearing makes an acoustic noise, therefore acoustic signals have also been investigated [7]. In order of investigation the bearing fault related spectrum components the sound spectrum at the frequency range between $10 \mathrm{~Hz}$ and $20 \mathrm{kHz}$ is being analyzed. Compared to the aforementioned methods, this one has got specific advantages and disadvantages. The main advantage of the method is a complete non-invasion. Installation of an acoustic shield during recording of acoustic signals is a drawback. Besides, the above method is not recommended to be used in a room where several motors operate simultaneously. Whilst the amount of vibration is evaluated using accelerometer data, inaccuracies may occur.

In order to avoid possible inaccuracies, a method of using a laser sensor for displacement has been developed [8]. Although the results are precise and errors avoided, the displacement sensor must be mounted on the bearing.

Chemical composition analysis of the bearing's oil is also used for bearing fault detection. Under high- temperature conditions, various substances are released in oil, and if the bearings are worn out, detection of small particles/impurities in oil, caused by the contacting elements, is possible. Analysis of bearing oil electrical properties are investigated [9]. Therefore, the method can only be applied to large motors (50 $\mathrm{kW}$ and more) with forced bearing lubrication. In small and medium-sized motors, the chemical oil analysis method is not applicable as it is impractical.

The increased temperature of bearings also informs about the failure. The IEEE 841 standard specifies that the temperature of the fully charged motor bearing shall not exceed $45^{\circ} \mathrm{C}$ above the ambient temperature. Temperature based method is not reliable, as the increased temperature can also be influenced by an increase of frame temperature [10]. The main disadvantage of the method is the complexity of temperature sensor installation.

A method of detection of a bearing fault by use of high-speed camera and an audio signal is presented in [11]. A high- speed camera is used for calculation of a shaft rotation angle. An acquired audio signal is then re-sampled to angular domains. The drawbacks of the method are the price of equipment and no possibility to detect GR fault. The advantage of the method is that computer vision and acquisition of audio signal makes it completely non-invasive.

A method which combines vibration and current analysis techniques is presented in [12]. Using the proposed method, we have a possibility of detection a bearing fault in the mechanical system, powered by IM. The drawback of the abovesaid technique is that only SP fault is detectable.

Stator current monitoring is a standard procedure in operation of an asynchronous motor. In most cases, current values are required for motor control and/or monitoring energy consumption. Voltage and current transformers are installed as components of the protection system. These sensors are standard components of motor control equipment. Recording of a current signal is a non-invasive procedure and can even be performed remotely i.e. from the operator's console. In addition, during a stator current analysis, not only a general motor state but also various faults can be observed. Calculation of rotor speed and motor efficiency is possible as well. The main disadvantage of this method is that the dominant component in the stator current spectrum is feeding frequency. As a result, difficulty of detection other, often much smaller, components arises. There exist a number of methods for detection SP bearing faults using stator current analysis, though so far identification of GR faults has been poorly investigated. Most of SP failure detection algorithms rely on identification of specific frequency component in the current spectrum. These methods can be divided into several groups. It is grouping of signals by applying a neural network, adaptive statistical time-frequency approach, wavelet decomposition, statistical discriminatory and extended Park's vector methods [13]. The method for the detection of bearing failure by neural network grouping is presented [14]. The stator current spectrum is calculated by the use of a Fast Fourier transform (FFT). A feature vector is created from the amplitudes of spectral points selected by an expert. Classification is performed by the use of Neural Network. An expert is not necessarily required for the analysis of records, but in order of smooth operation, a highly experienced professional is required to create rules for selecting spectrum points. Another method to detect motor failure is a time-frequency approach [15]. Therefore Short Time Fourier Transformation (STFT) is initially performed. By the use of statistical methods subsequent collection of vectors is classified in accordance with the state of the motor in time. Classified data are assigned to some motor status or faults. Wavelet decomposition is also being applied for bearing fault detection [16]. Spectrum points, carrying information related to bearing failures, are selected. Usage of wavelet coefficients enables calculation of the root mean square of the signal in the range. This study has been extended [17], and statistical methods were replaced by neural networks. General diagnostic tool for monitoring motor status has been developed as well [18]. The essence of the method is observation of the difference between time-frequency characteristics of healthy and faulty motor current signals. Evaluation is based on the first and the second-order filter response data. It has been proved that it is more difficult to diagnose bearing failures at partial and/or full load than at no-load. Method, which relies on the Park transformation of the stator's currents, enables diagnosing bearings malfunctions [19]. While other, 
stator current based methods usually rely only on one phase current, all three currents should be analyzed when applying the aforementioned method. Should be noted that [16-19] detects only SP faults.

Motor current signature analysis requires a high sampling rate and a large number of data samples for detection faults at light loading conditions. Vice versa the embedded systems used for on-line diagnosis are designed to perform with a relatively small number of data. Authors in [20] present a method of optimizing sample data size and complexity of calculations. The sub-Nyquist algorithm has been used for the achievement of the above goal. Though the method is suitable for detection of various faults, the GR fault is undetectable.

In order to remove fault unrelated current components, a current noise cancellation method has been introduced [21]. The developed method considers fundamental and its odd harmonics in the current signal to be the main component of noise. This technique enables a possibility of detection four kinds of SP faults. The basic disadvantage of the above method is that it is unsuitable for detection of a GR fault.

The analysis of methods for the identification of a GR bearing failure has demonstrated that there exist just a few methods and studies. The mentioned shortage of methods and studies has possibly occurred due to the fact that evenly distributed bearing defects do not generate a clear component in the frequency spectrum. The method named "mean spectrum deviation" [22] also applies a current signal. Filters are used to eliminate electrical grid frequency, eccentricities and rotor bars harmonics. The average value of the filtered motor current spectrum is the feature that helps to identify the failure. Although the method seems to be trustworthy, it has also got some drawbacks. First of all, it requires specific knowledge for identification of the required components of the spectrum. Secondly, it is assumed that the filtered parts of the signal do not carry information about the fault. Furthermore, one needs to know the rotation speed and some other parameters of the motor. Because only one method [22] of all reviewed, deals with GR fault identification using stator current, it can be assumed that GR fault identification via stator current analysis is a complicated problem and it is in an early stage of developing.

\section{Methods}

The Induction Motor can be powered from the electrical grid or by applying a variable frequency drive (VFD). The most popular frequency converters use the V/f control method. The operation of this converter is based on the fact that the ratio of voltage and frequency remains constant. A VFD has been used in the presented study.

The suggested method determines a GR bearing fault by the use of a stator current signal. For signal analysis, discrete wavelet transform and unique properties of Welch's spectral density have been used. The flowchart of the proposed method is presented in Fig. 1.

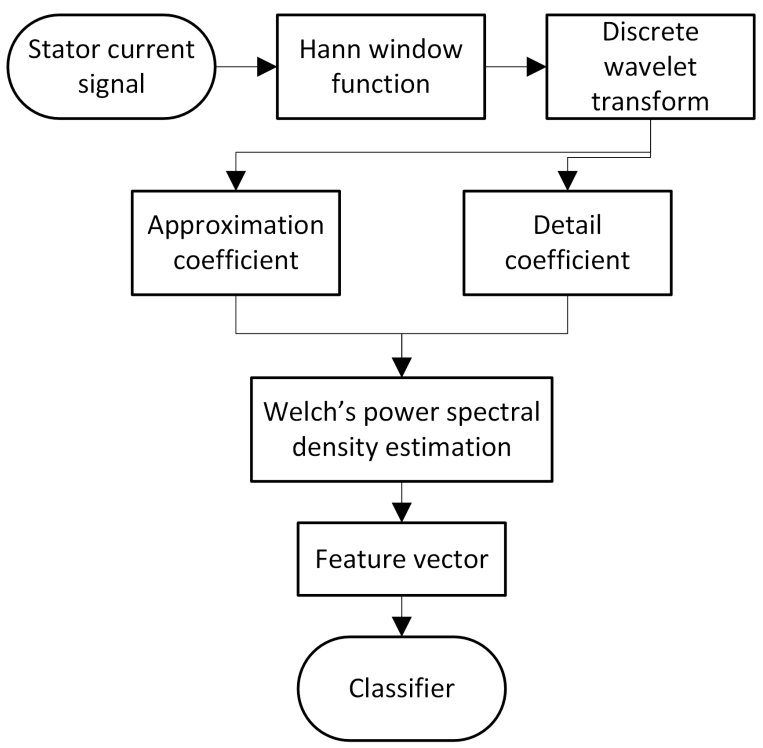

Fig. 1. Flowchart of proposed method.

Flowchart represents the way the features are selected from stators current signal. Further, a brief description of each step is presented.

1. Recording of stator phase current signal using current transducer at no-load state. Signal is used as an input. Sampling frequency: $F_{\mathrm{s}}=8192 \mathrm{~Hz}$.

2. Application of window function to a stator current signal. After testing various discrete window functions, Hann window was selected as most suitable:

$$
w(n)=0.5\left(1-\cos \left(2 \pi \frac{n}{N-1}\right)\right)
$$

where $w$ - Hann function, $N$ - length of a window, $0 \leq n \leq N$.

3. Application of discrete wavelet transform. Level 4 decomposition is performed by using Meyer wavelets.

4. Computation of $4^{\text {th }}$ level approximation and detail coefficients.

5. Estimation of Welch's power spectral density of level $4^{\text {th }}$ approximation and detail coefficients.

6. Forming the feature vector (Tab. 1). Vector consists of rms, mean and median as well as 3 and 6 maximum values ( 3 for detail and 6 for approximation) and prominences (how much the peak stands out due to its intrinsic height and its location relative to other peaks), in descent order. To increase performance, the array of 24 elements was normalized to the range of $[-1,1]$.

7. Classification. As an input a feature vector is used. In this paper classification is performed by the use of Support Vector Machine (SVM) classifier with linear kernel function. 


\begin{tabular}{|c|c|c|}
\hline No. & Feature & Source \\
\hline 1 & rms & \multirow{3}{*}{$\begin{array}{l}\text { approximation } \\
\text { coef. }\end{array}$} \\
\hline 2 & mean & \\
\hline 3 & median & \\
\hline 4 & rms & \multirow{3}{*}{ detail coef. } \\
\hline 5 & mean & \\
\hline 6 & median & \\
\hline $7-12$ & 6 max values & \multirow{2}{*}{$\begin{array}{l}\text { approximation } \\
\text { coef. }\end{array}$} \\
\hline $13-18$ & prominences of max values & \\
\hline $19-21$ & 3 max values & \multirow{2}{*}{ detail coef. } \\
\hline $22-24$ & prominences of max values & \\
\hline
\end{tabular}

Tab. 1. Feature vector structure

Discrete Wavelet Transform (DWT), Welch's power spectral density and SVM are being discussed below.

Discrete Wavelet Transform is a highly accurate mathematical tool for analysis of digital signal. Application of DWT represents a signal through a linear combination of their basis function. The wavelets must be oscillating, limited in duration and their mean must be a zero. Basis function of wavelet is as follows:

$$
\Phi_{(s, l)}(t)=2^{-\frac{s}{2}} \Phi\left(2^{-s} t-l\right)
$$

where $\Phi(t)$ - is mother function or sometimes called analyzing wavelet, $t$ - discrete number, $s$ is the scale index, which indicates the wavelet's width, while $l$ is location index, which indicates it's position.

To span our data domain at different resolutions, the wavelet is used in a scaling equation (3):

$$
W(t)=\sum_{i=-1}^{N-2}(-1)^{i} r_{i+1} \Phi(2 t+i)
$$

where $W(t)$ is scaling function for the mother function $\Phi$, $r_{i}$ are the wavelet coefficients. The coefficients $\left\{r_{0}, \ldots, r_{n}\right\}$ have been included into a transformation matrix, which is applied to a raw data vector. The coefficients are ordered using two dominant patterns $(g(k)$ and $h(k)$ Fig. 2) [23]. These two groups are respectively stated as approximation and $d e$ tail.

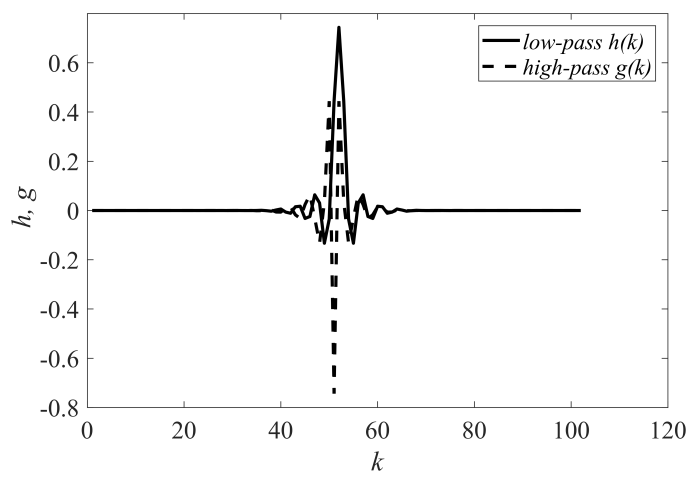

Fig. 2. Meyer wavelet low-pass and high-pass filters coefficients for decomposition.
There are many types of mother wavelet functions such as Coiflet, Daubechies, Haar, Meyer, etc. As a rule the functions have been selected according to the form of the signal being analyzed and shall be as close as possible. A scale is inversely proportional to the signal frequency, which means that the more compressed signal corresponds to a higher frequency. By applying a DWT, the signal is filtered and the sampling frequency is reduced (Fig. 3). In the figure $i_{s \text {.hann }}$ is a stator current signal presented, after application of Hann window function, $h(k)$ and $g(k)$ represent low-pass and highpass filters, while $c A_{s}$ and $c D_{s}$ - approximation and detail coefficient at $s$ level.

These coefficients can be obtained by:

$$
\begin{gathered}
c_{(s, l)}=\int_{-\infty}^{\infty} i_{s \cdot h a n n}(t) W(t) \mathrm{d} t, \\
c_{S}(t)=\sum_{l} c_{(s, l)} W(t) \mathrm{d} t .
\end{gathered}
$$

Starting with level 1 and with the next and each following stage, the approximation coefficient is once again split into two coefficients - approximation and detail. This process is being repeated several times until the desired level of transform is reached. The approximation coefficients correspond to high scale and low frequency compositions, while detail correspond to low scales and high frequencies. For most signals, low frequency components are the core.

Welch's method [24] is used (also described as the periodogram method) for estimating power spectra and is carried out by dividing the signal $c$ (in our case $c A_{s}$ or $c D_{s}$ ) into $P$ successive blocks, forming the windowed periodogram for each block:

$$
S_{p}(f)=\left|\sum_{m=1}^{M} c_{p}(m) q_{p}(m) \mathrm{e}^{-\mathrm{j} 2 \pi f m}\right|^{2}
$$

where $S_{p}$ - periodogram of $p$ block, $M$ - length of signal, $q_{p}$ - window function, $1 \leq m \leq M$. The power spectral density (Welch's periodogram) is an average of available periodograms:

$$
S_{c}(f)=\frac{1}{P} \sum_{p=1}^{P} S_{p}(f) .
$$

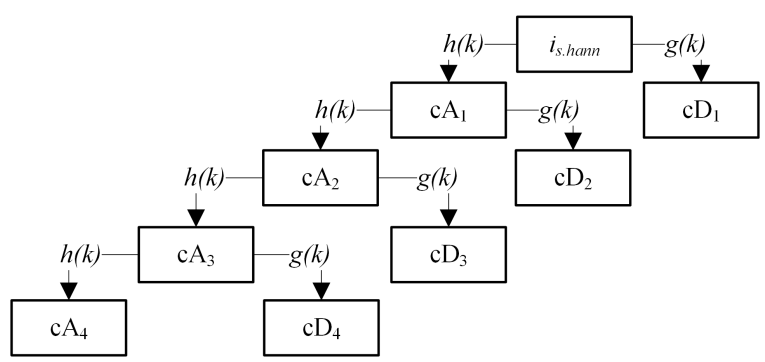

Fig. 3. Block diagram of discrete wavelet transform at level 4 applied in proposed algorithm. 
In order to reduce the large fluctuations of the periodogram [26], the Welch's algorithm relies on the division of the data sequence into segments. Welch's power spectral density of approximation and detail coefficients is presented in Fig. 4. Local maximums of spectral density are used as features for GR fault identification.

Computations are performed using Matlab, further, the prominence calculations steps are presented:

1. Place a marker on the peak of signal plot;

2. Extend a horizontal line from the peak to the left and right until the line does one of the following:

(a) Crosses the signal curve because there is a higher peak;

(b) Reaches the left or right end of the signal curve;

3. Find the minimum of the signal in each of the two intervals defined in Step 2. This point is either a valley or one of the signal endpoints;

4. The higher of the two interval minima specifies the reference level. The height of the peak above this level is its prominence.

SVM is supervised machine learning method that was firstly proposed for two classes separation problem. Original SVM algorithm was invented by Vladimir N. Vapnik in 1963. The current standard incarnation (soft margin) was proposed by Corinna Cortes and Vapnik in 1993 and published in 1995 [27]. The effectiveness of SVMs depends on the selection of Kernel function. Kernel scale and regularization parameters also considered as important. SVM training and testing has been performed.

The experiment was performed in order to validate the proposed algorithm. Details of experiments are presented in the below section.

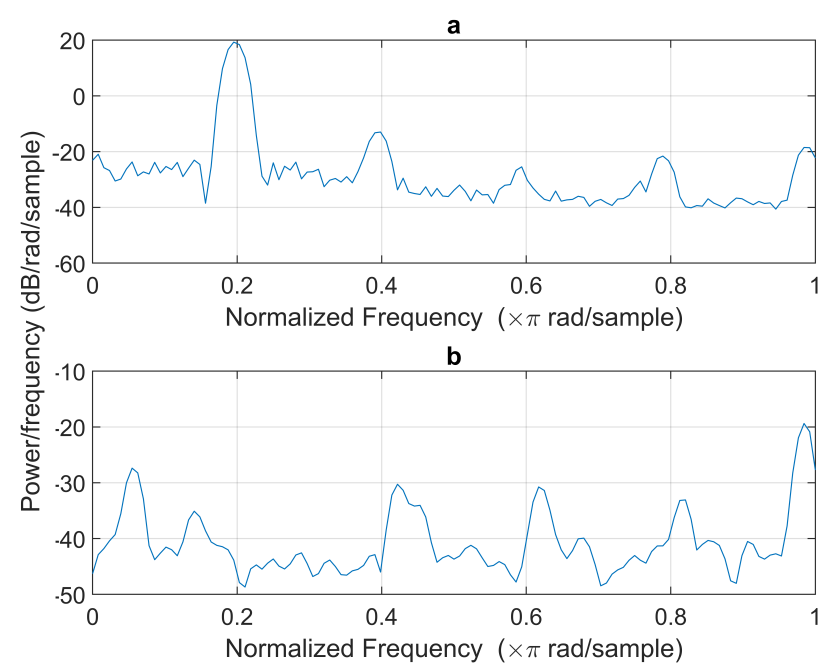

Fig. 4. Welch's power spectral density of $4^{\text {th }}$ level approximation (a) and detail (b) coefficients.

\section{Experiment}

The experiment was conducted in order to validate the proposed method. The $1.1 \mathrm{~kW}$ power, three-phase IM, with no load, was used in the study. The parameters of particular motor are given in the Tab. 2. The VFD has been controlled by the V/f method. Stator current signals of healthy and artificially damaged bearing have been recorded. Three-phase stator current signals have been used for feature (Tab. 1) extraction. The features have been used for training and testing SVM classifier model. Data for training and testing have been divided into two equal parts. Fault types and existence of GR fault symptoms are presented in Tab. 3 .

Artificially SP failures have been caused by damage to the inner railway, cage, and the outer railway of bearing. Accordingly, the GR failures have been caused by the removal of oil and the addition of impurities to the oil. A total of six signal types have been registered (including "healthy" bearing, artificial damage is not included). Each type of test has been performed at a ranging speed.

The speed has been altered by changing the frequency set point on the VFD's control panel. Selected frequency points are equal to $f_{\mathrm{s}}=10,20,30,40,50 \mathrm{~Hz}$. The upper limit was set according to nameplate data (Tab. 2). Rotational speed has been changed with the aim of investigation the proposed method performance dependency on speed. Current transformers "SCT013" and rotary encoder "LPD3806-600BM" have been respectively used for capturing of the current and rotational speed signals. The signals have been logged using an external data logger "Measurement computing USB-204" at sampling frequency of $F_{\mathrm{S}}=8192 \mathrm{~Hz}$. For the purpose of reducing uncertainty 100 signals have been recorded, for each case of the test. The total duration of the individual signal has been $1 \mathrm{~s}$. Total 3000 signals have been recorded during the experiment.

\begin{tabular}{|c|c|}
\hline Power $[\mathrm{kW}]$ & 1.1 \\
\hline Voltage $[\mathrm{V}]$ & $220 / 380$ \\
\hline Pole pairs & 3 \\
\hline Frequency $[\mathrm{Hz}]$ & 50 \\
\hline Rotation speed $[\mathrm{rpm}]$ & 1000 \\
\hline
\end{tabular}

Tab. 2. Parameters of IM

\begin{tabular}{|l|l|l|}
\hline No. & Fault type & GR fault Y/N \\
\hline 1 & no artificial demage & 0 \\
\hline 2 & $\begin{array}{l}\text { SP, inner raceway. } \\
\text { No GR symptoms }\end{array}$ & 0 \\
\hline 3 & $\begin{array}{l}\text { SP, cage. } \\
\text { No GR symptoms }\end{array}$ & 0 \\
\hline 4 & $\begin{array}{l}\text { SP, outer raceway. } \\
\text { No GR symptoms }\end{array}$ & 0 \\
\hline 5 & $\begin{array}{l}\text { GR, oil shortage. } \\
\text { GR symptoms }\end{array}$ & 1 \\
\hline 6 & $\begin{array}{l}\text { GR, impurities in oil. } \\
\text { GR symptoms }\end{array}$ & 1 \\
\hline
\end{tabular}

Tab. 3. Bearing fault type of tested cases. 
As it has been mentioned before, that feature vector after normalization (linear rescale) has been in the range of $[-1,1]$. The distribution of $7^{\text {th }}$ and $20^{\text {th }}$ normalized features is presented in Fig. 5. According to Tab. 1 the $7^{\text {th }}$ feature represents the largest peak at Welch spectral density of approximation coefficient, while $20^{\text {th }}$ - the second largest peak at Welch spectral density of detail coefficient. The above figures demonstrate, that though a few mismatches exist, most of the points are clustered into two groups and can be easily separated.

The classifier performance, at a different rotational speed has been tested, while applying the features of the proposed method. Five parameters have been used for evaluation of performance. Parameters have been calculated using the confusion matrix Tab. 4.

Accuracy represents the ratio of correctly classified versus the whole population (8). Sensitivity (9) and specificity (10), respectively, is the ratio of healthy identified as healthy and faulty identified as faulty. In literature sensitivity and specificity may be referred as True Positive Rate (TPR) and True Negative Rate (TNR). False Negative Rate (FNR)(11) and False Positive Rate (FPR)(12), is the ratio of faulty identified as healthy and healthy identified as faulty, respectively.

$$
\begin{aligned}
& \text { accuracy }=\frac{T P+T N}{T P+F P+F N+T N}, \\
& \text { sensitivity }=T P R=\frac{T P}{T P+F N}, \\
& \text { specificity }=T N R=\frac{T N}{T N+F P}, \\
& F N R=\frac{F N}{F N+T P}=1-T P R, \\
& F P R=\frac{F P}{F P+T N}=1-T N R .
\end{aligned}
$$

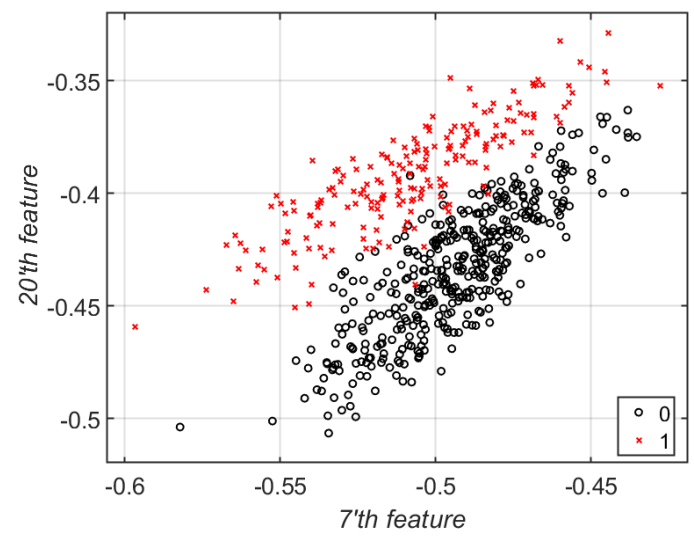

Fig. 5. Distribution of features 7 and 20 at $f_{\mathrm{s}}=50 \mathrm{~Hz}$. $7^{\text {th }}-$ largest peak at Welch spectral density of approximation coefficient, $20^{\text {th }}$ - second largest peak at Welch spectral density of detail coefficient.

\begin{tabular}{|l|l|l|l|}
\cline { 3 - 3 } \multicolumn{2}{c|}{} & \multicolumn{2}{|l|}{ Actual class } \\
\cline { 3 - 4 } \multicolumn{2}{c|}{} & Healthy & Faulty \\
\hline \multirow{2}{*}{ Predicted class } & Healthy & $T P$ & $F P$ \\
\cline { 2 - 4 } & Faulty & $F N$ & $T N$ \\
\hline
\end{tabular}

Tab. 4. Confusion table/matrix

\section{Results}

Results of performance have been presented in Tab. 5 . The case of supply frequency $f_{\mathrm{s}}=30 \mathrm{~Hz}$ has no successful identification of a fault, so it is clear that performance of this case is the worst. Best results of performance have been reached at supply frequency of $f_{\mathrm{s}}=50 \mathrm{~Hz}$, when $99 \%$ of samples have been classified to a correct class. Performance results in other cases (except $f_{\mathrm{s}}=[30,50] \mathrm{Hz}$ ) are low.

TPR of cases $f_{\mathrm{s}}=[10,20,40]$ are directly dependent upon supply frequency. It means that the closer rotational speed to nominal the higher rate of healthy can be identified as healthy. TNR are indirectly dependent upon supply frequency. Slower rotational speed shows the higher rate of faulty identified as faulty.

\begin{tabular}{|l|l|l|l|}
\hline$f_{\mathrm{s}}, \mathrm{Hz}$ & accuracy & $T P R(F N R)$ & $T N R(F P R)$ \\
\hline 10 & 0.69 & $0.87(0.13)$ & $0.33(0.67)$ \\
\hline 20 & 0.68 & $0.89(0.11)$ & $0.28(0.72)$ \\
\hline 30 & 0.67 & $1.00(0.00)$ & $0.00(1.00)$ \\
\hline 40 & 0.68 & $0.92(0.08)$ & $0.22(0.78)$ \\
\hline 50 & 0.99 & $0.99(0.01)$ & $0.99(0.01)$ \\
\hline
\end{tabular}

Tab. 5. Confusion results of proposed method at various speed.

\section{Conclusions}

The study presents a new method for identification of GR bearing fault by use of a stator current signal. The algorithm relies on Discrete Wavelet Transform and Welch's spectral density algorithm. Composition of both methods has been used for building a feature vector for the classifier. SVM classifier, with linear kernel function, has been applied to perform the classification. The presented experiment has been performed in order to validate the proposed method.

The evaluated experiment results stated the following: the GR fault can be identified via stator current signal at a $99 \%$ accuracy at the specific rotational speed. The proposed method is rotational speed dependent. For the achievement of more exact results further research of decomposition level dependency on rotational speed is required.

\section{References}

[1] THOMSON, W., FENGER, M. Current signature analysis to detect induction motor faults. IEEE Industry Applications Magazine, 2001, vol. 7, no. 4, p. 26-34, ISSN: 1077-2618. DOI: 10.1109/2943.930988 
[2] ROMERO-TRONCOSO, R., J., SAUCEDO-GALLAGA, R., CABAL-YAPEZ, E., et al. FPGA-Based online detection of multiple combined faults in induction motors through information entropy and fuzzy inference. IEEE Transactions on Industrial Electronics, 2011, vol. 58, no. 11, p. 5263-5270. ISSN: 0278-0046. DOI: $10.1109 /$ TIE.2011.2123858

[3] STACK, J., R., HABERTLER, T., G., HARLEY, R., G. Fault classification and fault signature production for rolling element bearings in electric machines. IEEE Transactions on Industry Applications, 2004, vol. 40, no. 3, p. 735-739. ISSN: 0093-9994. DOI: 10.1109/TIA.2004.827454

[4] LI, B., CHOW, M., Y., TIPSUWAN, Y., et al. Neural-network-based motor rolling bearing fault diagnosis. IEEE Transactions on Industrial Electronics, 2000, vol. 47, no. 5, p. 1060-1069. ISSN: 0278-0046. DOI: $10.1109 / 41.873214$

[5] ISO 10816-8:2014. Mechanical Vibration - Evaluation of Machine Vibration by Measurements on Non-Rotating Parts - Part 1: General Guidelines.

[6] HAWMAN, M., W., GALINAITIS, W., S. Acoustic emission monitoring of rolling element bearings. In Proceedings of the IEEE Ultrasonics Symposium (IUS). Chicago (USA), 1988, p. 885-889. DOI: $10.1109 /$ ULTSYM.1988.49503

[7] SUN, D., XU, Z., YUAN, Y., J. Detection of abnormal noises from tapered roller bearings by a sound sensing system. In Proceedings of the 24th International Conference on Mechatronics and Machine Vision in Practice (M2VIP). Auckland (New Zealand), 2017, p. 1-4. ISBN: 978-1-5090-6546-2. DOI: 10.1109/M2VIP.2017.8211504

[8] SHAO, Y., NEZU, F. Bearing fault detection using laser displacement sensor. In Proceedings of the 35th SICE Annual Conference. Tottori (Japan), 1996, p. 1069-1072. ISBN: 0-7803-3751-4. DOI: $10.1109 /$ SICE. 1996.865411

[9] JOSHI, A., BLENNOW, J. Electrical characterization of bearing lubricants. In Proceedings of the Conference on Electrical Insulation and Dielectric Phenomena (CEIDP). Des Moines (USA), 2014, p. 586-589. ISSN: 0084-9162. DOI: 10.1109/CEIDP2014.6995856

[10] MARU, B., ZOTOS, P., A. Anti-friction bearing temperature rise for NEMA frame motors. In Proceedings of the Petroleum and Chemical Industry Conference (PCIC). Dallas (USA), 1989, p. 883-888. DOI: 10.1109/PCICON.1988.22438

[11] LU, S., GUO, J., HE, Q., et al. A novel contactless angular resampling method for motor bearing fault diagnosis under variable speed. IEEE Transactions on Instrumentation and Measurement, 2016, vol. 65, no. 11, p. 2538-2550. ISSN: 0018-9456. DOI: $10.1109 /$ TIM.2016.2588541

[12] SINGH, S. KUMAR, N. Detection of bearing faults in mechanical systems using stator current monitoring. IEEE Transactions on Industrial Informatics, 2017, vol. 13, no. 3, p. 1341-1349. ISSN: 1551-3203. DOI: 10.1109/TII.2016.2641470

[13] ZHOU, W., HABETLER, T., G., HARLEY, R., G. Stator current-based bearing fault detection techniques: A general review. In Proceedings of the IEEE International Symposium on Diagnostics for Electric Machines, Power Electronics and Drives (SDEMPED). Cracow (Poland), 2007, p. 7-8. ISBN: 978-1-4244-1061-3. DOI: 10.1109/DEMPED.2007.4393063

[14] SCHOEN, R., R., LIN, B., K., HABETLER, T., G., et al. An unsupervised, on-line system for induction motor fault detection using stator current monitoring. IEEE Transactions on Industry Applications, 1994, vol. 31, no. 6, p. 1280-1286. ISSN: 0093-9994. DOI: $10.1109 / 28.475698$
[15] YAZICI, B., KLIMAN, G., B. An adaptive statistical time-frequency method for detection of broken bars and bearing faults in motors using stator current. IEEE Transactions on Industry Applications, 1999, vol. 35, no. 2, p. 442-452. ISSN: 0093-9994. DOI: $10.1109 / 28.753640$

[16] EREN, L., DEVANEY, M., J. Bearing damage detection via wavelet packet decomposition of the stator current. IEEE Transactions on Instrumentation and Measurement, 2004, vol. 53, no. 2, p. 431-436. ISSN: 0018-9456. DOI: 10.1109/TIM.2004.823323

[17] EREN, L., KARAHOCA, A., DEVANEY, M., J. Neural network based motor bearing fault detection. In Proceedings of the IEEE Instrumentation and Measurement Technology Conference (I2MTC). Como (Italy), 2004, p. 1637-1657. ISSN: 1091-5281. DOI: 10.1109/IMTC.2004.1351399

[18] ILONEN, J., KAMARAINEN, J., K., LINDH, T., et al. Diagnosis tool for motor condition monitoring. IEEE Transactions on Industry Applications, 2005, vol. 41, no. 4, p. 963-971. ISSN: 0093-9994. DOI: 10.1109/TIA.2005.851001

[19] SILVA, J., L., H., CARDOSO, A., J., M. Bearing failures diagnosis in three-phase induction motors by extended Park's vector approach. In Proceedings of the 31st Conference of IEEE Industrial Electronics Society (IECON). Raleigh (USA), 2005, p. 2591-2596. ISSN: 1553-572X. DOI: 10.1109/IECON.2005.1569315

[20] NAHA, A., SAMANTA, A. K., ROUTRAY, A., et al. Low complexity motor current signature analysis using sub-Nyquist strategy with reduced data length IEEE Transactions on Instrumentation and Measurement, 2017, vol. 66, no. 12, p. 3249-3259. ISSN: 0018-9456. DOI: 10.1109/TIM.2017.2737879

[21] DALVAND, F., DALVAND, S., SHARAFI, F., et al. Current noise cancellation for bearing fault diagnosis using time shifting. IEEE Transactions on Industrial Electronics, 2017, vol. 64, no. 10, p. 8138-8147. ISSN: 0278-0046. DOI: 10.1109/TIE.2017.2694397

[22] STACK, J., R., HABETLER, T., G., HARLEY, R., G. Bearing fault detection via autoregressive stator current modeling. IEEE Transactions on Industry Applications, 2004, vol. 40, no. 3, p. 740-747. ISSN: 0093-9994. DOI: 10.1109/TIA.2004.827797

[23] GRAPS, A. An introduction to wavelets. IEEE Computational Science and Engineering, 1995, vol. 2, no. 2, p. 50-61. ISSN: 1070-9924. DOI: $10.1109 / 99.388960$

[24] WELCH, P. The use of fast Fourier transform for the estimation of power spectra: A method based on time averaging over short, modified periodograms. IEEE Transactions on Audio and Electroacoustics, 1967, vol. 15, no. 2, p. 70-73. ISSN: 0018-9278. DOI: $10.1109 /$ TAU.1967.1161901

[25] SMITH, J., O. Spectral Audio Signal Processing. [Online] Cited 2018-04-27. Available at: https://www.dsprelated.com/freebooks/sasp/

[26] STOICA, P. MOSES, R., L. Spectral Analysis of Signals. New Jersey (USA): Prentice Hall, 2005. ISBN: 0131139568

[27] CORTES, C., VAPNIK, V. Support-vector networks. Machine Learning, 1995, vol. 20, no. 3, p. 273-297. ISSN: 0885-6125. DOI: $10.1007 / \mathrm{BF} 00994018$ 


\section{About the Authors ...}

Ignas ANDRIJAUSKAS was born in Panevezys. He is pursuing Ph.D. from the Dept. of Electric Power Systems, Kaunas University of Technology. He received his M.Sc. in 2012. His research interests include induction motor faults detection and classification.

Mindaugas VAITKUNAS received his M.Sc., and Ph.D. in Electrical and Electronics Engineering from the Kaunas University of Technology (Lithuania) in 1998 and 2002 respectively. Since 2006, he is an Assoc. Professor at the Dept. of Electrical Power Systems at KTU. His main research inter- ests include investigation of efficiency and control of electrical power converters, switch mode power supplies for LED lighting, smart sensors and signal processing.

Rimas ADASKEVICIUS is working as a Professor at the Dept. of Electric Power Systems, Kaunas University of Technology. He received Ph.D. degree in Technological Science at Kaunas University of Technology in 1997. His research interest include development of new picture and signal processing methods and equipment, design of factory automation equipment, development of 3D scanners, software for 3D model applications, thermal cameras and software for processing of thermal images, investigation of induction motor control methods and equipment. 